\title{
Developing seasonal rainfall scenarios for food security early warning
}

\author{
Gregory J. Husak • Christopher C. Funk • \\ Joel Michaelsen • Tamuka Magadzire • \\ Kirk P. Goldsberry
}

Received: 27 April 2012 / Accepted: 14 January 2013 / Published online: 30 January 2013

(C) The Author(s) 2013. This article is published with open access at Springerlink.com

\begin{abstract}
Rainfed agriculture in Sub-Saharan Africa accounts for $95 \%$ of the local cereal production, impacting hundreds of millions of people. Early identification of poor rainfall conditions is a critical indicator of food security. As such, monitoring accumulated seasonal rainfall gives an important midseason estimate of final accumulated totals. However, characterizing the remaining uncertainty in a season has largely been ignored by the food security community. This paper presents a new technique describing rainfall conditions over the duration of a crop-growing cycle by combining estimated rainfall-todate with potential scenarios for the remaining season based on available satellite rainfall estimates, the common tool for rainfall analysis in Africa. The limited historical record provided by satellite rainfall estimates using previous seasons provides only a coarse view of likely seasonal totals. To combat this, scenarios developed by bootstrapping dekadal data to create synthetic seasons allow for a finer understanding of potential seasonal accumulations. Updating this throughout the season
\end{abstract}

G. J. Husak $(\bowtie) \cdot$ C. C. Funk · J. Michaelsen

Department of Geography, University of California,

Santa Barbara, CA 93106-4060, USA

e-mail: husak@geog.ucsb.edu

C. C. Funk

Earth Resources and Observation Science Center,

U.S. Geological Survey,

47914 252nd Street,

Sioux Falls, SD 57198-0001, USA

\section{T. Magadzire}

Southern African Development Community,

Famine Early Warning Systems Network,

Plot No. 54385, Central Business District, Private Bag 0095,

Gaborone, Botswana

K. P. Goldsberry

Department of Geography, Michigan State University,

673 Auditorium Road, Room 116 ,

East Lansing, MI 48824, USA shows a narrowing envelope of seasonal totals, converging on the final seasonal result. The resulting scenarios inform the expectations for the final seasonal rainfall accumulation, allowing analysts to quantify and visualize the uncertainty in seasonal totals. Giving decision makers a tool for understanding the likelihood of specific rainfall amounts provides additional time to enact and mobilize efforts to reduce the impact of agricultural drought.

\section{Introduction}

Much of the developing world relies heavily on rainfed agriculture. In Sub-Saharan Africa, rainfed farms account for $95 \%$ of the local cereal production (Wani et al. 2009), employing $70 \%$ of the people (Gelb and World Bank 2000; Wani et al. 2009). When widespread drought strikes crops, millions of people, mostly women and children, face hunger. Such was the case in 2009 when poor rainfall contributed to an increase of 53 million food-insecure people in Sub-Saharan Africa, according to the annual "State of Food Insecurity in the World" publications by FAO (Food and Agriculture Organization of the United Nations 2008, 2009). Fortunately, effective early warning in 2009 helped to provoke effective food aid responses, totaling 3.6 million metric tons ${ }^{1}$. Effective and early rainfall monitoring, based on satellite rainfall estimates (Funk et al. 2003; Artan et al. 2007), plays an important role in guiding humanitarian responses. These estimates, while imperfect (Dinku et al. 2008), capture the spatial patterns of rainfall, and can be compared against previous years to identify anomalous rainfall (Funk and Verdin 2009). As the satellite record increases with time, there is a more robust archive of

\footnotetext{
$\overline{{ }^{1} \mathrm{http} / / / \text { documents.wfp.org/stellent/groups/public/documents/news }}$ room/wfp223563.pdf.
} 
estimates to compare with current values. Exploiting this historical information effectively can lead to more accurate and timely drought early warning, saving lives and livelihoods, and limiting the economic disruptions produced by extreme weather. This paper attempts to combine crop phenology information and satellite-based rainfall estimates to quantify crop-specific rainfall accumulations in a probabilistic framework. Monitoring rainfall over the course of the growing cycle of a crop provides a proxy for crop performance that can be compared to other seasons in the satellite record. Generating end-of-season results using rainfall from previous years to fill out a season helps to define both the expectation and variability in the remainder of the crop-growing season. This variability gives a sense for the uncertainty related to the estimated expectation, an important element for decision makers to determine the appropriate response.

The following section describes the rainfall estimates and how the season is parameterized using this rainfall. Then, a brief evaluation of seasonal rainfall totals based on the satellite rainfall record is described for Southern Africa, highlighting regimes prone to rainfall-related crop yield reductions. Section 3 details the scenario monitoring technique with an example from the 2009-2010 growing season for Southern Africa. The results are displayed through a series of maps presenting different characterizations based on the scenario analysis. Section 4 steps through the season for a single administrative zone of Zimbabwe, capturing the narrowing cone of uncertainty, includes a validation of the technique by comparing end-of-season conditions to the forecast range developed in mid-season, and raises potential issues going forward. The final section summarizes the major findings and potential applications of this research.

\section{Background}

Current estimates show that nearly 160 million people are undernourished in Sub-Saharan Africa (Food and Agriculture Organization of the United Nations 2011). In Southern Africa, more than one in three people face undernourishment. Food aid to Sub-Saharan Africa in 2010 accounted for nearly twothirds of all global food aid, with $72 \%$ of the received amount coming in the form of "Emergency Aid" (World Food Programme 2011). Providing tools for analysis to inform decisions regarding the correct amount of aid and timeframe for delivery to prevent undernourishment can directly impact millions of lives.

The analyses presented in this report are based on the National Oceanic and Atmospheric Administration (NOAA) satellite rainfall estimates (RFE2) (Xie and Arkin 1997). The RFE2 integrates daily rainfall observations, geostationary infrared cold cloud duration rainfall fields, and passive microwave rainfall retrievals to produce $0.1^{\circ}$ daily grids of rainfall for Africa. While satellite rainfall fields are associated with significant bias in areas of complex terrain (Dinku et al. 2008), this bias can be reduced using high-resolution climatologic rainfall fields (Funk et al. 2007) to track agricultural crop water deficits (Funk and Verdin 2009). Furthermore, in areas without much complex topography such as Zimbabwe, the RFE2 has been shown to be a preferred rainfall estimate (Dinku et al. 2008). The RFE2 drives a number of monitoring products used in the food security analysis such as the standardized precipitation index (SPI) and water requirement satisfaction index (WRSI). The ability to use RFE2 for quantitatively monitoring food security in Africa is affirmed in literature (Tadross et al. 2005; Verdin et al. 2005; Sawunyama and Hughes 2008; Tadesse et al. 2008).

Algorithms exist to utilize RFE2 data to establish some seasonal parameters for Africa. Onset of rains establish the start of season (SOS) for each location. Detection of SOS for Southern Africa begins in September, which is the earliest possible planting date. This research uses the technique developed in West Africa (AGRHYMET 1996) and reinforced in WRSI literature (Verdin and Klaver 2002; Senay and Verdin 2003), defining SOS as the first dekad receiving $25 \mathrm{~mm}$ of rainfall, followed by two dekads summing to $20 \mathrm{~mm}$. While there may be local deviations from this as a viable SOS, it is a widely supported approximation (Tadross et al. 2005; Tadesse et al. 2008; Funk and Budde 2009; Crespo et al. 2011; Harrison et al. 2011).

Rainfall data also factors into determining the length of growing period (LGP). The LGP "for each pixel is determined by the persistence, on average, above a threshold value of the climatological ratio between rainfall and potential evapotranspiration," Early Warning Systems Network (FEWS NET). This identifies the portion of the year when water is typically available for crop growth, defined as the time of the year when rainfall is sufficient to support plant development, as measured by evapotranspiration. The duration of this portion of the year defines the LGP. For some northern areas of Southern Africa, LGP calculated by this measure could be in excess of 20 dekads, an unrealistic growing duration for maize, the primary crop. Work on implementing the WRSI with national meteorological and agricultural services in the region resulted in feedback on LGP durations that more accurately reflect the practices in the field. For the purposes of this research, locations with a calculated LGP longer than 16 dekads have been set to 16 dekads (Fig. 1). This limit comes from local input and common monitoring practices in the region, as identified by regional scientists, and is

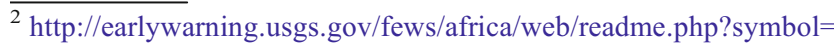
cl.
} 
Fig. 1 Length of growing period (LGP) for the Southern Africa growing region

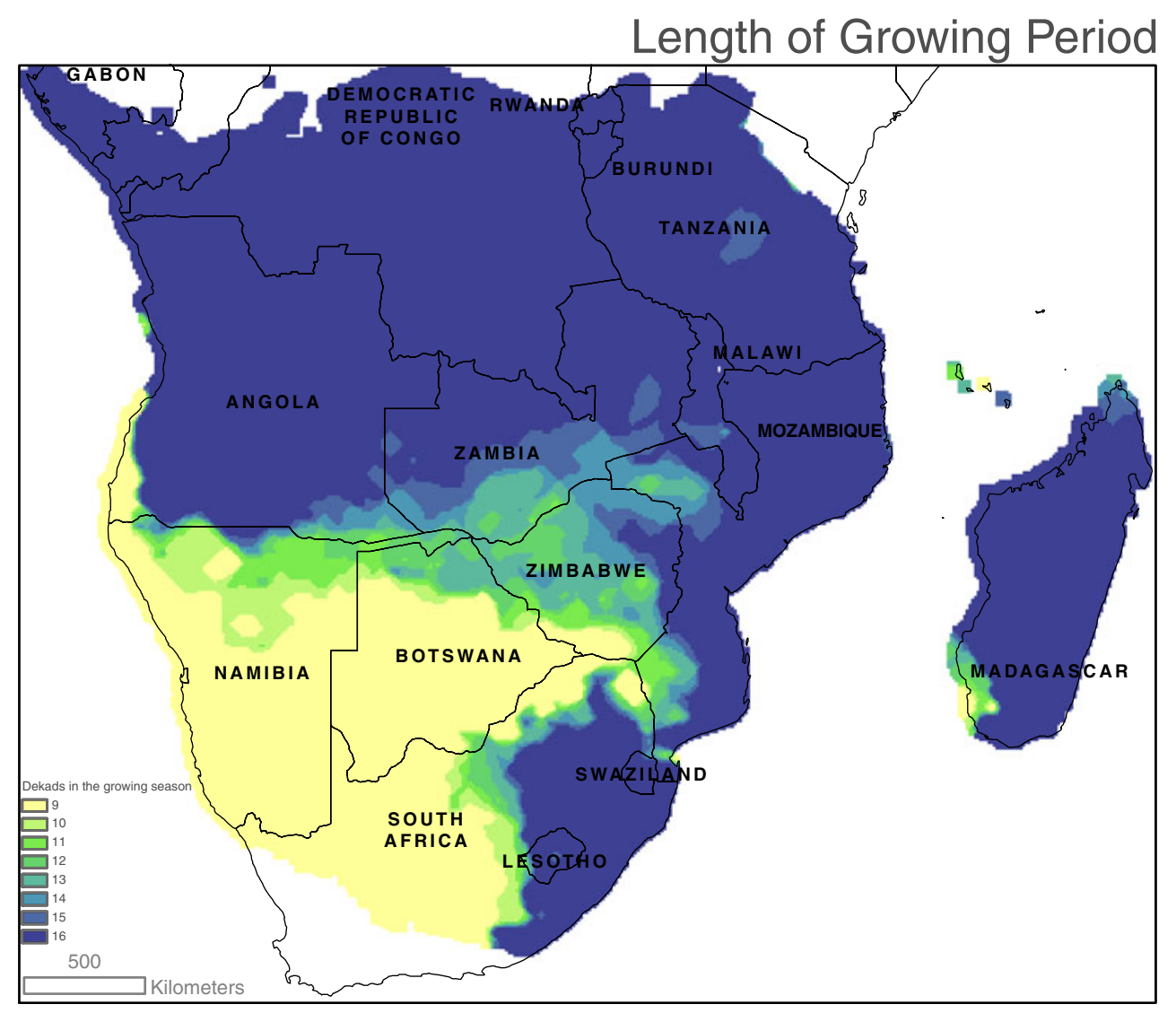

supported by seed catalogs suggesting maize varieties to be grown in the region. This LGP work borrows heavily from the WRSI crop model implemented by the U.S. Geological Survey (USGS) (Senay and Verdin 2003) and FEWS NET.

The WRSI is a measure of the fraction of the water demand of a crop that is being met by soil moisture and rainfall (Frere and Popov 1986; Senay and Verdin 2003; Verdin and Klaver 2002). The WRSI incorporates components of rainfall, potential evapotranspiration, and soil moisture. Additionally, a crop coefficient specific to the crop type determines the water demand of the crop for the phonological cycle, from the SOS for the entire LGP. The WRSI is a leading indicator of crop yield in monitoring African food production and is therefore a logical product to use in defining growing season characteristics for this study. It should be noted that for many regions, there is a good correspondence between seasonal rainfall totals, what this study investigates, and end of season WRSI values (Verdin et al. 2005).

In this paper, climatological LGP is used to define the duration of accumulation of rainfall following the onset of rains. This interval varies with respect to the calendar each year as a function of the SOS, but the duration, as defined by LGP, is fixed for each location. This combination of onset and duration defines a "season" in this study. Portions of Southern Africa have complex seasonal calendars, some involving multiple seasons. For the purposes of this research, analysis occurs for a single season for which monitoring begins in September and involves only one LGP.

Rainfall regimes in Southern Africa cover a wide spectrum of possibilities, from consistently very wet locations in the north to highly variable rainfall in the south. The LGP map presented in Fig. 1 gives an approximation of the rainfall regimes by highlighting the duration for which rainfall can support plant growth. The map of the coefficient of variation, the standard deviation divided by the mean, for rainfall during the growing period from the historical RFE2 record (2000-present; Fig. 2) captures the spatial patterns of rainfall and the seasonal variability. This map shows that in the northern areas of the region, there is little variability, relative to the mean, on a seasonal scale. These locations receive large amounts of rain, such that even substantial seasonal rainfall anomalies are small with respect to the average condition over the 16 dekads of accumulation. In a practical sense, these areas receive enough rainfall to support agriculture, and any food shortage is not rainfall related. In the southern, semi-arid areas, the coefficient of variation is large. This variability with respect to a relatively small mean indicates a vulnerability of food production to rainfall, as seasonal totals range from abundant rainfall, easily capable of supporting agriculture, to a lack of rainfall, insufficient enough to even establish a start of season. This latter case is represented in the southwest fringes of the 
Fig. 2 Coefficient of variation for seasonal rainfall totals accumulated during the cropgrowing season according to RFE2

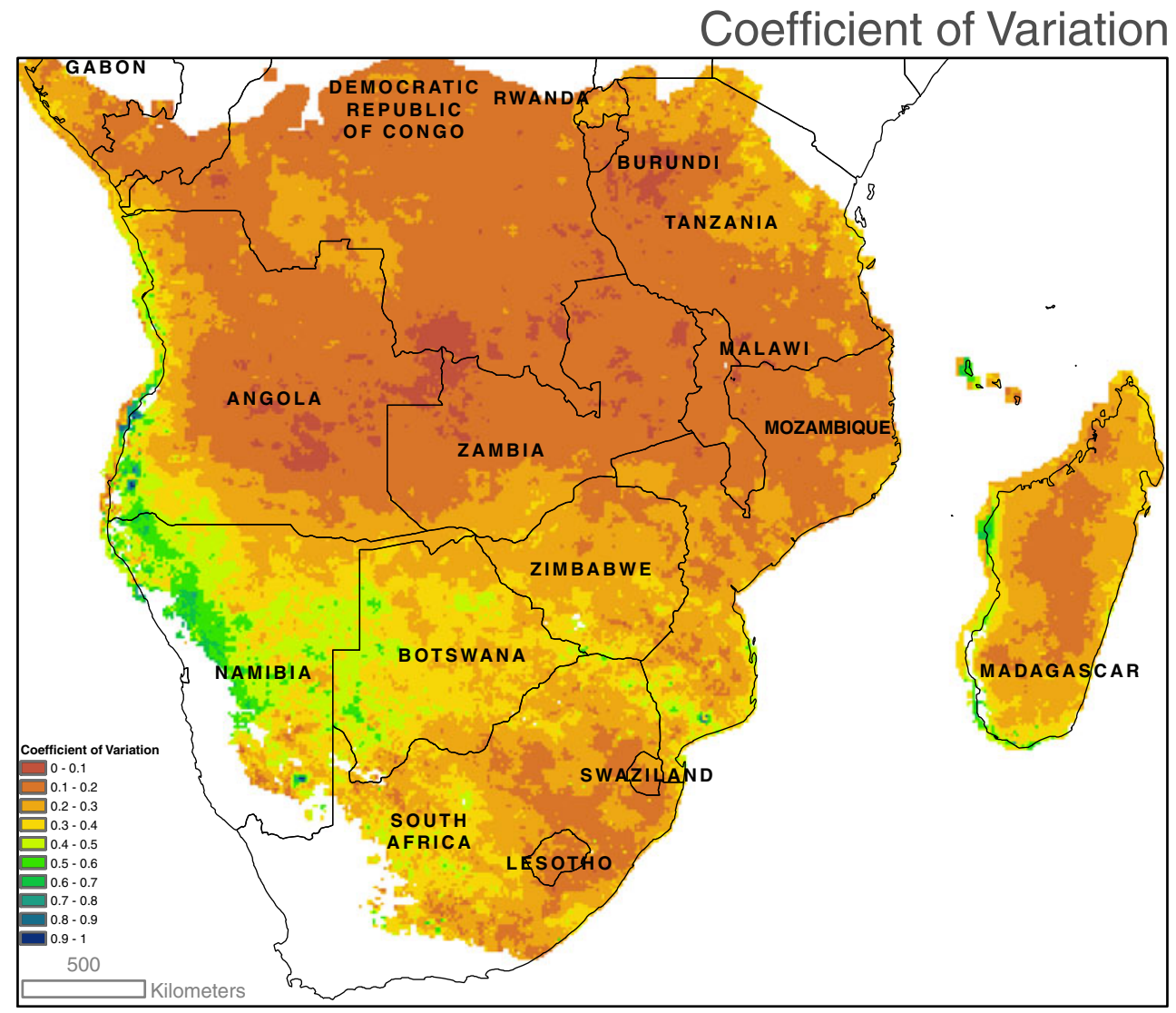

growing area in Fig. 2, where seasons that did not experience and onset of rains received $0 \mathrm{~mm}$ of rainfall for the season. Applications of the techniques presented in this paper are most critical in the semi-arid regions where the success of crops is tightly tied to rainfall variability.

While the variability in potential seasonal totals at the time of SOS for a location may be large, as the season progresses, the range of potential totals shrinks due to the reduced time for accumulation. Eventually, the season ends, and no variability in seasonal totals remain. While monitoring in-season rainfall values may foretell of bad seasonal conditions, it is possibly more important to estimate the likelihood of end-of-season values. For instance, it may be that early season conditions are above average, but with much variability remaining in the season, there is a high likelihood of the season ending below average. However, later in that season, while the relative performance of the season has remained equally above average, there may be a very small chance of rainfall ending below average.

Putting an envelope on the potential totals for a season, and conveying this information to decision makers, leads to increased warning of extreme end-of-season conditions. This type of monitoring leads to improvements in the mobilization of relief, better estimates of market conditions, and the activation of mechanisms to mitigate the impacts of poor rainfall and crop performance.

\section{Methods and results}

This section describes the techniques used to monitor the growing season rainfall performance using the RFE2 history and synthetic scenarios generated from a bootstrapping technique for Southern Africa. The results of these techniques, and an evaluation of their performance, are presented for the 2009-2010 growing season. Scenarios are compared against actual end-of-season rainfall totals to determine the value of the proposed technique in capturing these values in the middle of the season. By showing a direct application, the reader ascertains the value of incorporating this analysis in monitoring and the early warning potential of these techniques. For the purpose of contextualizing the described techniques, examples define the monitoring point as accumulation through the third dekad of January 2010.

Monitoring the rainfall for the onset of rains is performed by a number of organizations. Notably, this is done by the USGS using the technique laid out by Senay and Verdin (2003) and available for viewing on the Africa Data Dissemination Server (ADDS). ${ }^{3}$ The results of the SOS for the Southern Africa region for the 2009-2010 growing season, as calculated from the RFE2, are shown in Fig. 3.

\footnotetext{
${ }^{3} \mathrm{http}: / /$ earlywarning.usgs.gov/adds/.
} 
Fig. 3 Map of start of season (SOS) for the Southern Africa growing region for the 20092010 growing season

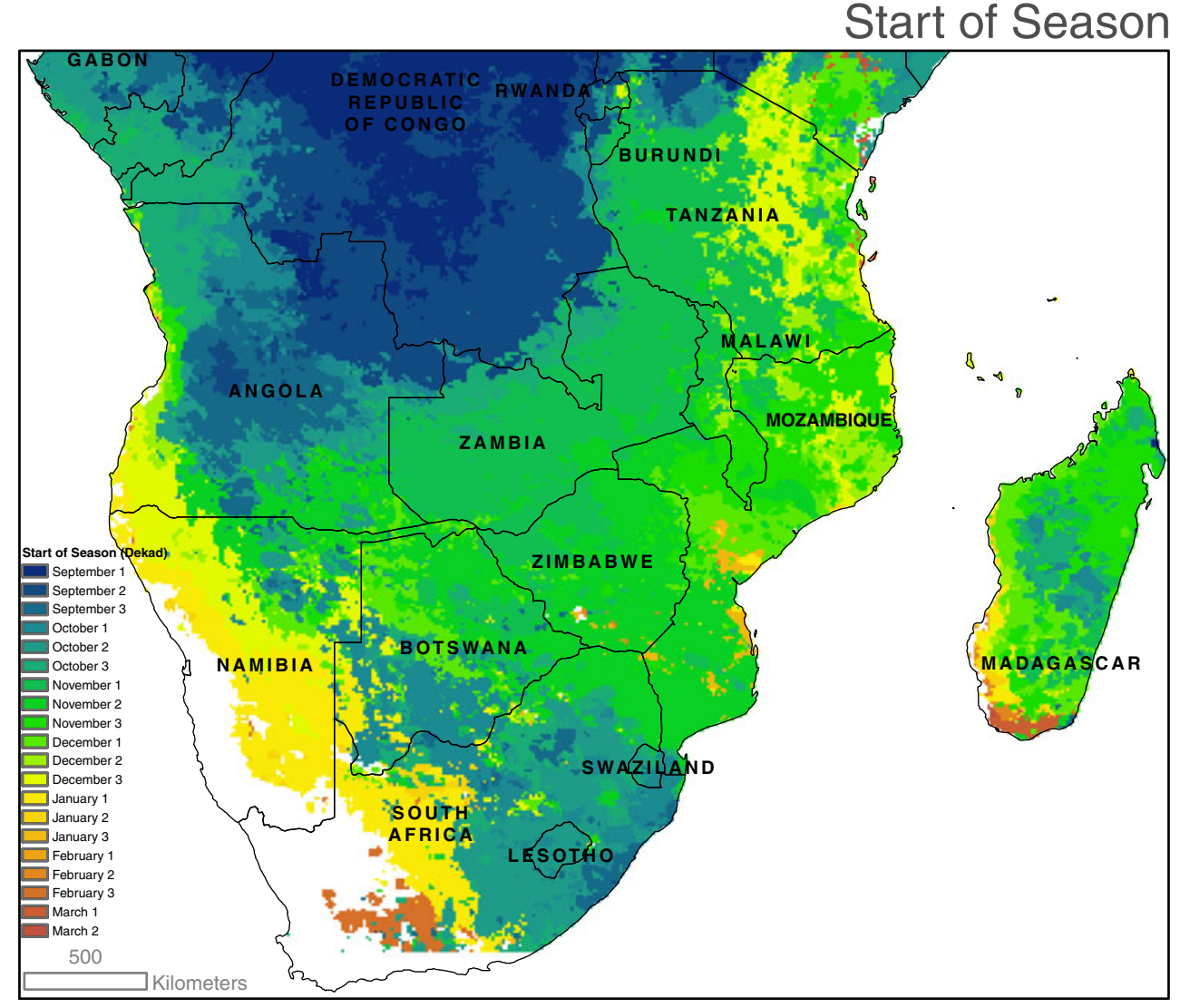

With the SOS determined from the RFE2 data, the number of dekads between the SOS and the monitoring point, the time within the growing season that monitoring is taking place (typically the most recent dekad), is determined. The amount of time from SOS to the monitoring point varies in space in accordance with the SOS, but can be defined as $n$ dekads, where $n$ is greater than zero at locations where the onset has occurred and cannot exceed LGP for a location. In this study, seasons that did not experience an onset of rains were excluded from the analysis. Summing the rainfall for $n$ dekads at each location gives the current season total. Comparing this seasonal total to date, shown in Fig. 4, to the mean accumulation for $n$ dekads following the SOS from previous years results in a relative performance of rainfall for season-to-date. This relative measure, shown in Fig. 5, averaged over the major crop production zones, allows the user to determine how the current season measures up against the mean performance from previous years.

It should be noted that this measure does not directly incorporate information related to early or late SOS. However, it is exactly because of this variable SOS that this measure yields more valuable information than comparing against the accumulation from a fixed calendar period. For instance, if the current year had an exceptionally early SOS, to compare that against a similar calendar period from previous years would likely show the current year as above average, since in prior years, there was not enough rainfall to initiate the SOS. Because of this, the location with the early start may have an additional two or more dekads of rainfall accumulation than the climatology would indicate. Assuming that the rainfall accounting method captures farmer planting and with the knowledge that seasonal rainfall totals are linked to crop performance, the resulting monitoring tool - the season-to-date percent of normal (PON) - improves on accumulations over calendar periods.

When monitoring rainfall for food security purposes, it is valuable to compare rainfall accumulations over the entire growing period of the crop to previous years. To fill seasonal totals for locations where $n$ is less than the LGP, the technique presented here utilizes the mean or median rainfall for the remainder of the season. Unlike the season-todate analysis, the projection of rainfall over the next LGP minus $n$ dekads (called "remaining period") is the same interval from previous calendar years. Combining rainfall totals from the remaining period of previous years with the season-to-date accumulation for the current season sums to an estimate of seasonal total. To derive a season PON, compare this seasonal estimate with the mean of previous seasonal totals.

The described analysis leverages temporal and historical characteristics to give more robust information about seasonal conditions and projections. The term "outcome" is 
Fig. 4 Accumulated rainfall, in millimeters, from SOS through the third dekad of January 2010
Fig. 5 Percent of normal map through the third dekad of January 2010

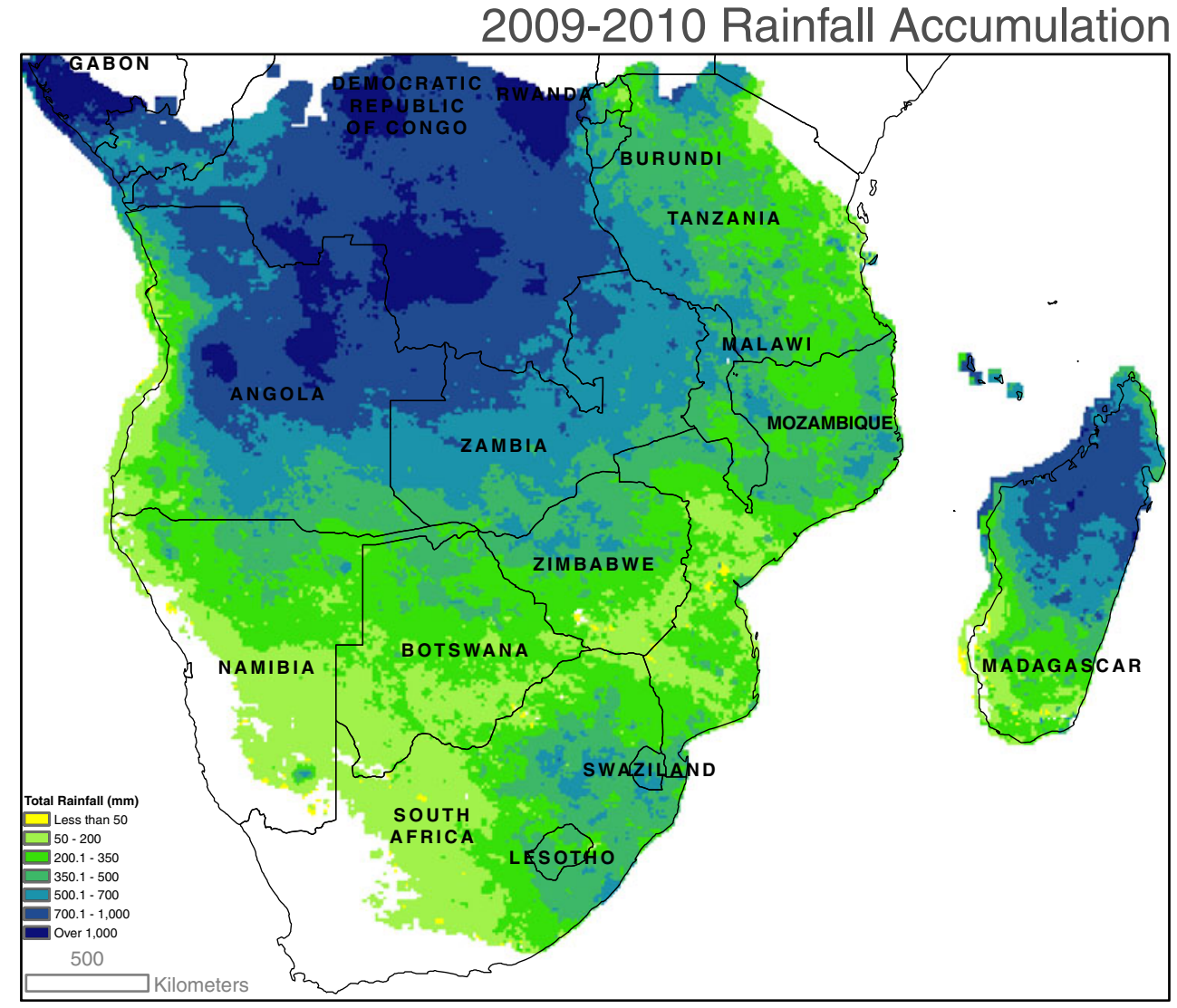

2009-2010 Rainfall: Percent of Normal

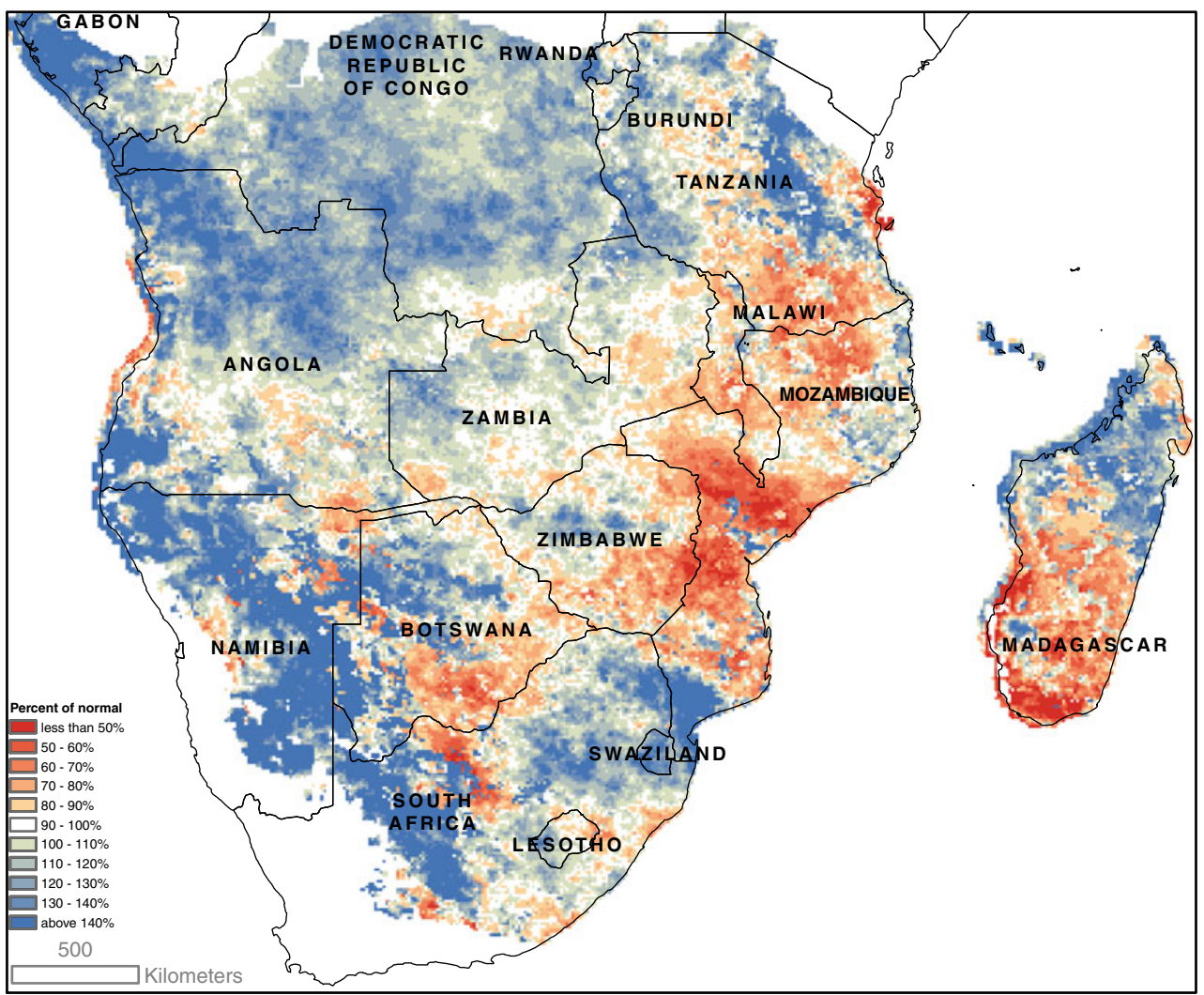


used to mean the total rainfall accumulated during an interval, typically the LGP but occasionally a subset of that. First, taking the mean accumulation over the remaining period for all previous years gives the expected outcome for the remainder of the season. Additionally, by using previous years, it is possible to also estimate the range of potential outcomes. Figure 6 shows the driest (lowest) and wettest (highest) seasonal outcomes, expressed as WRSI, using the previous years to fill the remaining season for the 2009-2010 growing season. In these maps, values close to 100 are areas where little water stress is experienced by the crop, while values below 50 indicate water-related crop failure. The difference between the maps is an indication of how much uncertainty in the crop yield is still to be determined by the rainfall remaining in the season. At locations where the values in the driest and wettest scenarios are similar, such as eastern Zambia (good crop condition) or southern Zimbabwe (poor crop condition), there is little uncertainty in the seasonal outcome, with respect to crop performance. Conversely, where the values are very different, such as northern Mozambique, there is a large range in potential crop performance for the season. Early in the season, the envelope of outcomes is quite large; however, as the season progresses and the variability in the remaining period contracts, the range of potential outcomes is similarly reduced.

A different depiction of the information from previous years counts the end of season PON values which are above or below a threshold. Figure 7 presents this count information using a trivariate map to express the likelihood of different rainfall accumulations in a single figure. This map uses a combination of rainfall estimates through the end of January 2010 and rainfall estimates from the nine
(2001-2009) previous years beyond February to fill the remainder of the season and develop a count of seasons which end as dry $(<85$ PON), normal $(>85$ and $<115$ PON), or wet ( $>115$ PON). Assessing how these nine combined seasonal totals are distributed among the three classes provides information about the likelihood of current seasonal totals being within one of these classes.

In describing how to interpret the map, it is best to start with just one class on the legend. Starting at the bottom axis of the triangle and moving towards the top vertex, there is an increase in the normal rainfall category. The bottom layer represents less than three of the nine events being in that normal class, resulting in it being "least likely." The next layer up is the "somewhat likely" category, corresponding to three to five events being in this class of seasonal total. Finally, the top triangle is for when more than five of the nine potential outcomes result in this "normal" class, making it the "most likely" seasonal total for a location. When this top level occurs, the other classes are in the "least likely" category. Just as there is increasing likelihood of the "normal" class as the user goes from the base axis to the top vertex, there is also an identical relationship for the "dry" class from the right axis to the lower-left vertex, and for the "wet" class from the left axis to the lower-right vertex. In this way, you can identify a categorical likelihood of any class for a point on the map.

If the counts at a location are evenly split among each class, then the distribution of outcomes in each category (dry/normal/wet) is equal. However, where the counts are predominantly in a single class, that location approaches an exterior vertex of the trivariate legend, as indicated by the more intense red/yellow/blue colors, with an anticipated increase in likelihood of that category and a corresponding
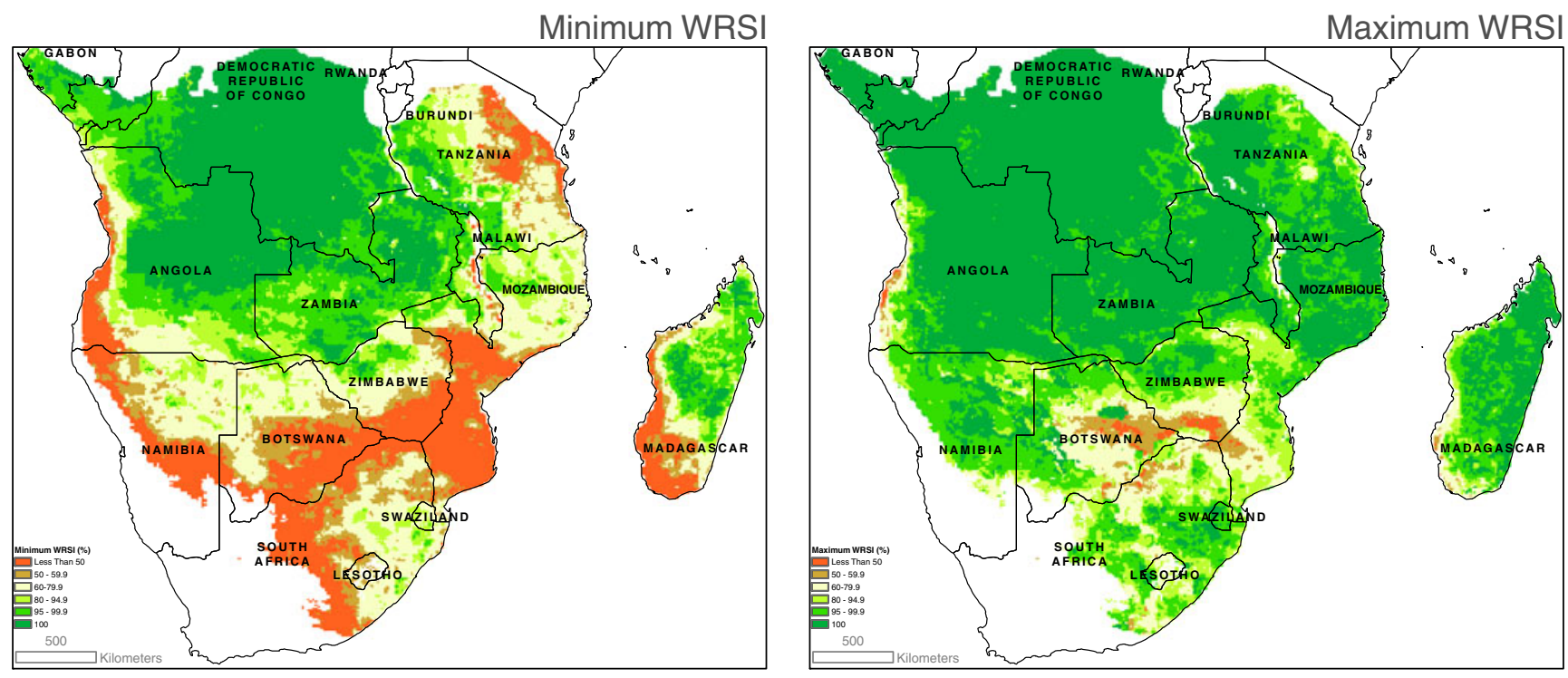

Fig. 6 Driest (left) and wettest (right) outcomes using previous years to fill out the remainder of the season 
Fig. 7 A trivariate map representing the number of seasons, based on previous years, that end as "dry" $(<85$ PON), "normal" ( $>85$ and $<115$ PON), or "wet" (>115 PON)

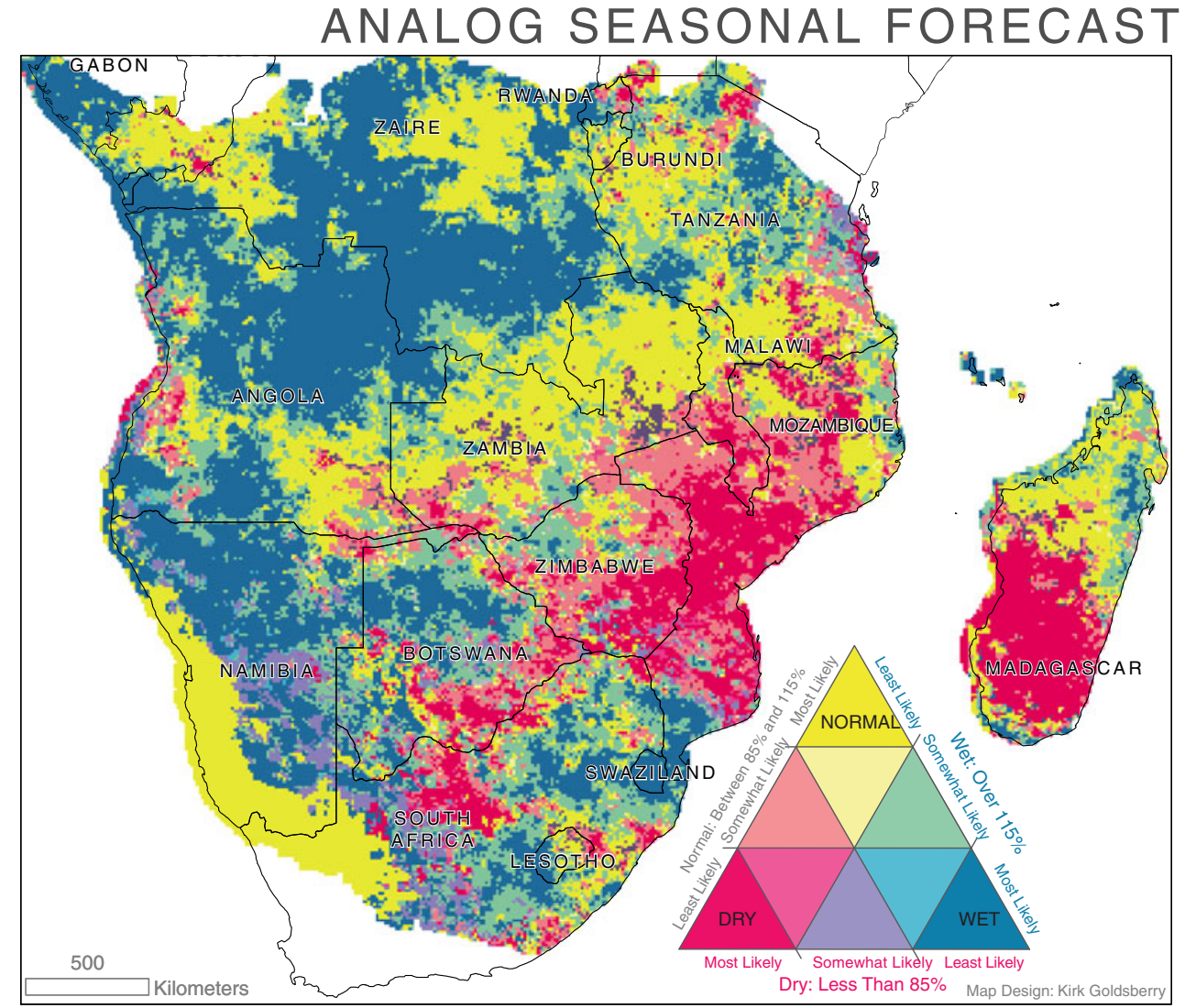

decrease in the others. As the season matures and variability in seasonal totals is reduced, all points on the map migrate towards the exterior vertices of the legend, indicating increased certainty of that class.

With the RFE2 product being limited to just over a decade of rainfall estimates, there is an absence of an extensive number of years to build a full array of potential seasonal outcomes. One way to simulate a large number of seasonal outcomes involves bootstrapping to build synthetic estimates of the remaining season. Built in to this bootstrapping technique is an assumption of independence between dekads. In order to test the independence of RFE2 dekadal data, detrended dekadal rainfall estimates during the rainy season (December-March) were analyzed for autocorrelation. The results of this showed that there is no statistically significant correlation between detrended dekadal rainfall. With the assumption of independence confirmed, filling out a season by selecting the rainfall for each dekad from a randomly selected prior year results in a synthetic season. Doing this many times over results in an array of potential seasonal outcomes, and provides the user with more information about the envelope of possibility for the season. More than just bounding the seasonal outcomes, using synthetic seasons provides finer detailed information, when compared to using just the nine previous seasons, about the likelihood of a given value being exceeded in the seasonal total. So, a user could estimate the PON rainfall that will be exceeded 4 out of 5 years, or determine the probability of rainfall greater than a certain PON. An example of this is shown in Fig. 8 where 100 synthetic seasons were created to map the value that will be exceeded four out of five times (left, 20th percentile) and one out of five times (right, 80th percentile). Where the values on the two maps are similar, little variability/uncertainty in the potential seasonal outcome exists. Where the value on the map on the left (right) is greater (less) than $100 \%$, there exists a high probability of rainfall being above (below) average. This information could be very valuable to decision makers as it leads to an early indication of locations which are likely facing seasonal rainfall totals that may not be sufficient for food production.

Use of previous years or synthetic seasons to fill out the remainder of a season offers a valuable tool for assessing seasonal rainfall. For instance, such analysis can offer likely seasonal totals and their corresponding WRSI by using the mean rainfall or even more tuned information by looking at how rainfall from specific years, appended to current seasonal totals, would result at the end of the growing season. The analysis presented here also provides information on the range of outcomes, and thus some indication of the uncertainty remaining in the season at a location. So, while the mean PON for two locations at the end of the season is 

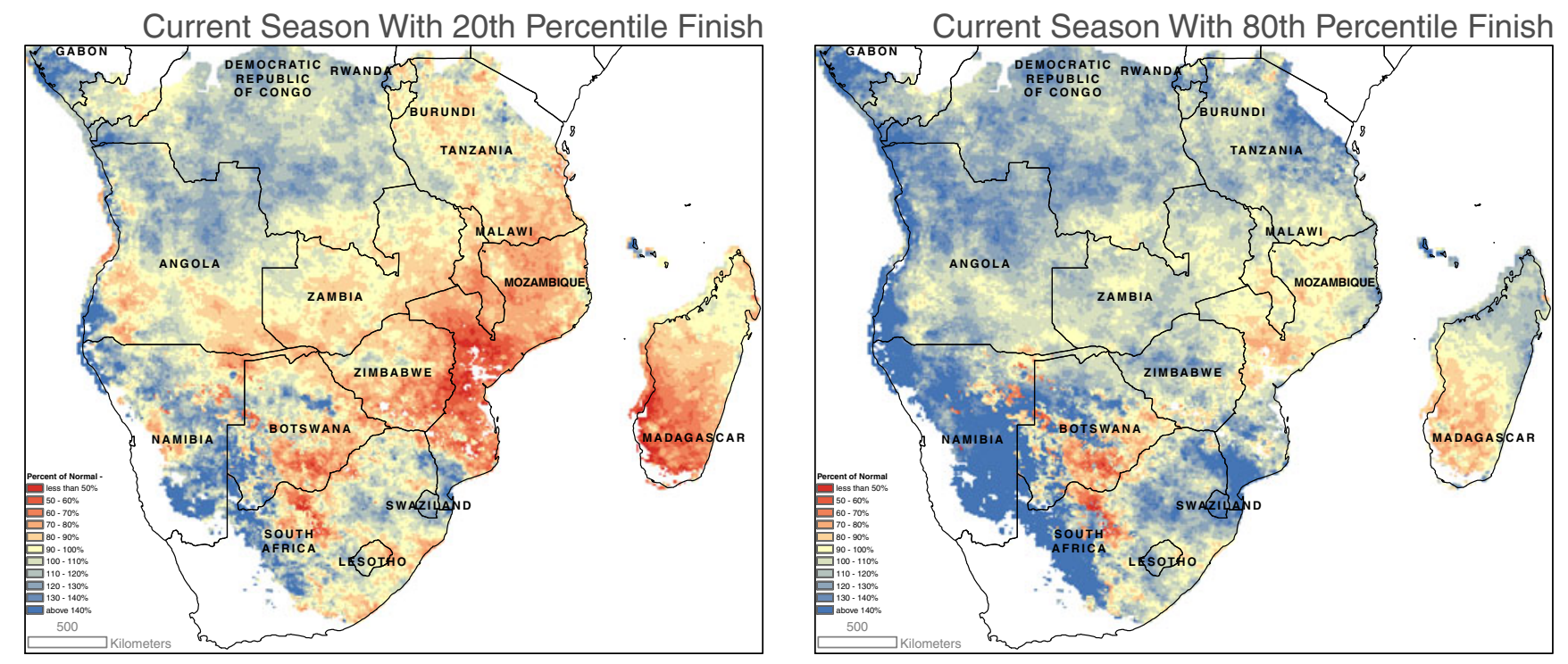

Fig. 8 Percent of normal amounts associated with the 20th percentile (left) and the 80th percentile (right)

the same, there would be a very different level of certainty if one location had a range of outcomes from $70 \%$ to $150 \%$ while the other ranged from $95 \%$ to $105 \%$. Finally, the use of bootstrapped synthetic seasons provides finer probabilistic information regarding the likelihood of certain PON values being exceeded. This can lead to an earlier determination of when the variability remaining in the growing season will have minimal influence on the seasonal outcome. All this information can lead to earlier and more informed decisions regarding the expectations for seasonal rainfall.

\section{Analysis and discussion}

This section will review a seasonal analysis for Southern Africa to highlight some of the strengths of the proposed technique, as well as show a practical example. Additionally, it provides a discussion of some shortcomings, potential improvements, and the sensitivity of this approach to the varying parameters related to seasonal timing. At the end, the reader will have a more thorough understanding of the benefits of this approach as well as potential applications.

An instructive way to understand the value of the proposed technique is to look at a single, homogenous growing area in Southern Africa. For the purposes of this paper, a province of northeast Zimbabwe (Mashonaland Central) has been selected as the monitoring region. In practice, this could be a watershed polygon, corresponding to agricultural areas or any other area of interest. This region was selected because it has low variability in the length of season at 1416 dekads, and also has a homogenous SOS for the 20092010 growing season of the second dekad of November.
These characteristics facilitate convenient areal analysis because it is possible to look and treat these timing parameters in a consistent way, rather than assessing fractions of the area for different SOS and LGP.

Figure 9 presents this pixel-level information for the whole administrative unit for the duration of the growing season. The gray boxplot captures the interquartile range and extremes using the preceding 9 years to fill out the remainder of the season, while the black boxplot shows the results generated using synthetic simulations to fill the remainder of the season. Both plots show that in the early part of the season, while the expectation for seasonal outcome may change somewhat with each passing dekad, the range of extremes and the interquartile range do not shrink significantly. However, as this plot shows, the range of outcomes reduces with each passing dekad, especially during the second half of the season. The range based on synthetic seasons before SOS (Nov-1) extends from 50 to 165 PON. By the second dekad of January, the halfway point of the season, this reduces to 65-140 PON, but only 1 month later (a month of good rain), that range shrinks even further from 85 to $125 \mathrm{PON}$.

The boxplots in Fig. 9 highlight the stability derived from using the synthetic simulations when the history of rainfall is relatively short. While the interquartile range and extremes using the nine previous seasons available from the RFE2 (gray boxplot) show considerable fluctuations, the simulations (black boxplot) allow for a consistent decrease in both the interquartile range and the extremes.

The seasonal progress of the variability remaining in the season is represented using a boxplot of synthetic scenarios in Fig. 9. Before the season starts (first dekad of November), analysis of Fig. 2 shows this area typically has a moderate 
Fig. 9 Progression of uncertainty in the remaining season for Mashonaland Central for the 2009/2010 growing season. Dekads are shown on the $x$-axis, with the median rainfall represented by the line in the box, and the box capturing the interquartile range of scenarios for the remaining season

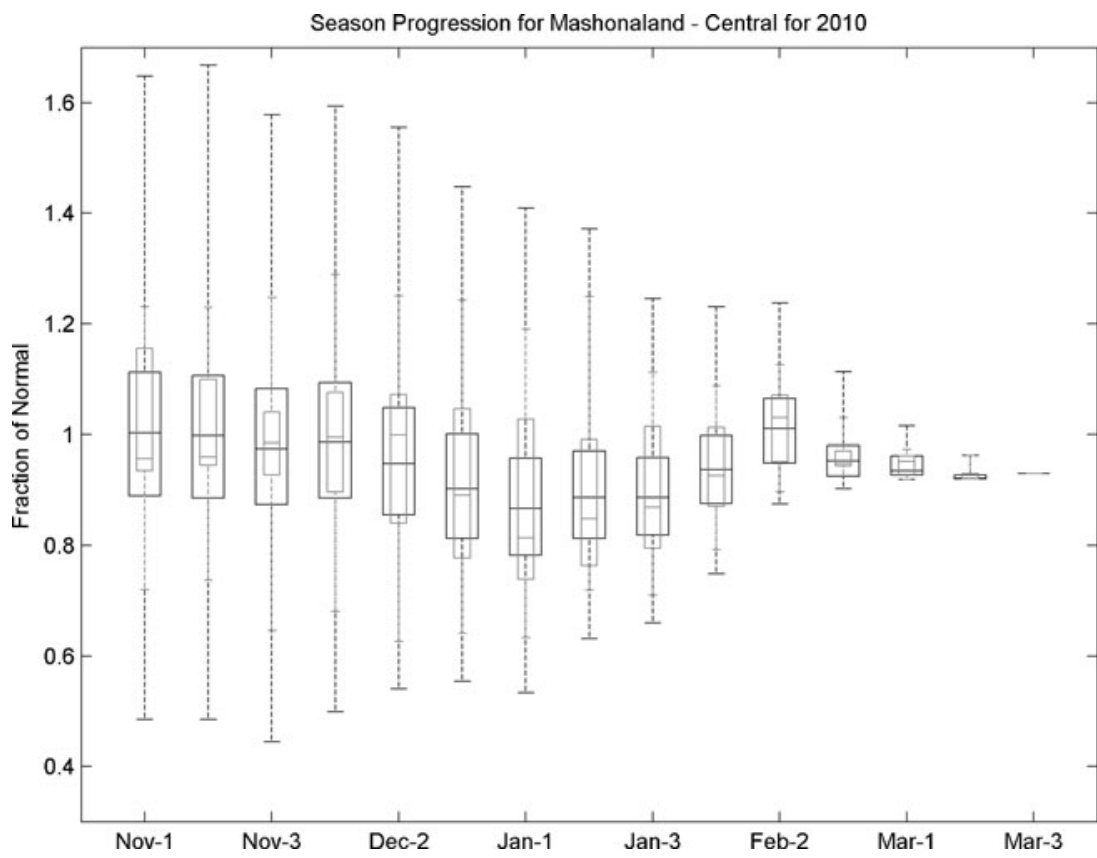

seasonal variability relative to the mean, with a standard deviation that is $20-30 \%$ of the mean rainfall. This moderate coefficient of variation is a function of the fairly large variability in rainfall amount being somewhat offset by large mean rainfall in this region. Once rains begin (November 2), a combination of RFE2 estimated rainfall for the season-todate and synthetic rainfall scenarios create estimates of seasonal total, and those totals are divided by mean rainfall over the LGP from previous seasons.

At the end of January 2010, this region experienced eight dekads since SOS, or just over half of the growing season. Figure 5 displays this area as a mix of normal and below normal conditions at this point in the season. Figure 9 confirms this with the median scenario (the black line in each box) projecting out to just under 90 PON, with the interquartile range extending from $80 \mathrm{PON}$ to $95 \mathrm{PON}$. The extent of the whiskers on the box at January 3 defines the envelope of potential possibilities for the region based on aggregated rainfall for the area. Figure 6 confirms the driest previous year results in moderate crop performance, and the wettest previous year results in crop performance that is quite good, as indicated by the WRSI. Figure 7 reveals much of the area to be "somewhat likely" for the dry class, and "least likely" for the normal and wet classes. From the gray boxplot in Fig. 9, we can estimate the counts of combined seasonal accumulations using rainfall from previous years that the region shows four to five events resulting in seasonal values below $85 \mathrm{PON}$ and the wettest event resulting in rainfall just greater than 115 PON at the January 3 point on the $x$-axis, confirming the interpretation of the trivariate map. Typically, it would be expected that roughly half the time rainfall would be greater than 100
PON, and half the time it would be less. These counts suggest that given the rainfall in the current season, there is a half chance of rainfall being greater than $85 \mathrm{PON}$, and a half chance of less than this value.

With this sort of information at the end of January, with about half of the growing period remaining, an estimate for Mashonaland Central could be made of rainfall most likely being normal to below normal, with a chance of extreme dryness. This sort of information, properly presented, could let decision makers know that there is a moderate chance that rainfall shortages will be a major factor in the crop yields for this growing season, but also a reasonable chance that things will be average. In fact, the seasonal rainfall accumulations for this area had a consistent second half of the season resulting in average to slightly below average seasonal rainfall over much of this region.

This paper does not attempt to make specific forecasts which can be validated in sense of looking at the difference in millimeters, but rather in providing decision makers with a range of seasonal totals or, more specifically, the probabilities of specific seasonal totals being exceeded. The use of a single previous year as an example serves as an introduction to the proposed methodology, but does not capture probabilities of outcomes. Using the suite of available previous years to help define the likelihood of dry, normal, or wet outcomes, as in Fig. 7, leverages multiple years, but is limited by the relatively short history of the RFE2 dataset. Bootstrapped seasons attempt to make up for this by generating many scenarios which can be used to derive finer resolution probabilities of outcomes as well as expand the range of events.

One limitation of this scenario development is that rainfall values are constrained to the working history of the 
RFE2. While, in sum, a scenario built on the bootstrapping technique may be more extreme than a seasonal total previously experienced-as displayed in Fig. 9 with the black whiskers extending beyond the gray whiskers - the individual dekads may not be more extreme. A simple validation of the tested growing year to determine how seasonal percent of normal values compared to bootstrapped scenarios can determine if scenarios provide realistic ranges of seasonal outcomes.

The validation implemented here was designed to test how well the scenarios generated after the third dekad of January captured the final season outcomes. Locations where the growing season was finished were excluded as there was no scenario to test. Additionally, locations where the historical minimum PON was greater than $80 \%$ were also excluded as this indicates that these areas are not drought prone. The first step was to capture the final season PON at each pixel by using the RFE2 data from the remainder of the season. Then, this PON was compared to the scenarios generated at each pixel to determine the percentile of that outcome based on the distribution of scenario outcomes. The distribution of these percentiles is expected to be uniform, indicating that the scenarios differentiate both the range and distribution of outcomes. In fact, while the distribution was not uniform, $49.28 \%$ of pixels had outcomes between the 25 th and 75 th percentile, $76.44 \%$ of pixels were between the tenth and 90th percentile, and $49.53 \%$ of pixels were less than the median scenario. What the scenario process failed to capture was the most extreme tails of the distribution, with $7.11 \%$ of pixels falling outside the range established by the bootstrapping technique. This disproportionate number of pixels outside the scenario range is resulting from two linked factors. The rainfall at some locations was extraordinary, unlike that seen in the historical RFE2 record, and also that the bootstrapping technique underestimates the actual variance of the remaining season. The link between these two factors is the relatively short period of RFE2, which cannot account for extreme events not represented in the historical record and also impacts the ability of the bootstrapping technique to accurately estimate the true variance in rainfall.

The validation reveals that the 10 -year record of the RFE2 does not appear to be sufficient to indicate the magnitude of extreme events. However, the scenario analysis, when performed at approximately the midpoint of the season, does a good job of capturing median events and bounding all but the most extreme seasonal events. The results of this validation give decision makers confidence in probabilistic estimates for all but the most extreme of outcomes.

Use of the RFE2 to determine SOS, while serving as a suitable approximation, may not accurately capture the true planting dates. Feedback from working with local experts implementing the WRSI has shown how changes in SOS can impact the seasonal WRSI values, resulting in efforts to capture information from field surveys to better represent planting. The research presented in this paper suffers from the same issues as the WRSI in this respect-if timing (SOS, LGP) and rainfall fields are incorrect, the results will be compromised - and better inputs should improve the outputs. This work partially accounts for this by using the consistent metric to determine SOS for each season rather than a fixed date, and presents outputs as PON rather than an absolute rainfall amount that may have a mean that is biased. These two factors should minimize the impact of incorrect SOS information because they attempt to represent results in a relative manner.

Deriving LGP using the climatic data incorporates some of the shortcomings associated with rainfall estimates as part of this field. The LGP is used as a surrogate for crop cycle length, which varies for different crop variety. As with the SOS, applications of the WRSI have shown the sensitivity of seasonal accounting to LGP and allows for user input LGP. The research presented in this paper allows for adjustments to the input LGP field, which can be tuned to local crop-growing practices. However, as an approximation and based on feedback from local agencies, the LGP used in the implementation for the presented research adequately captures general growing trends across the region.

Overall, this technique gives decision makers an additional tool for monitoring the seasonal progress and anticipated outcomes of a season. The monitoring example of analysis for rainfall through January shows how this technique results in both assessment maps describing the conditions since the onset of rains, and also how to use scenarios to bound potential outcomes and define likely ranges. Displaying this information in a variety of ways responds to different specific interests as well as answering different questions about the season. The progression and reduction of rainfall variability shown for Mashonaland Central presents scenario information for a specific geographic area, and gives the user an idea about how rainfall uncertainty is reduced throughout the season. The insight described by these products stands to not only identify areas facing abnormal conditions but also give decision makers tools to determine the severity and certainty of conditions earlier in the growing season.

\section{Summary}

While calendar periods provide a natural monitoring scale for evaluating rainfall, for agricultural purposes, in which the growing season varies with respect to the calendar year, it is more valuable to monitor over the growing season of the crop. The spatially varying nature of onset of rains and duration of the crop cycle over wide areas necessitates 
tracking these variables for smaller regions - pixels, administrative zones, and homogeneous agricultural areas. Comparing the current season with previous years gives a relative performance, contextualizing the current season. Projecting end of season values, using rainfall from previous years or synthetic blends of previous years combined with season-to-date totals, estimates the range of potential outcomes. As the season progresses, the range narrows, preparing decision makers for likely outcomes. With an eye towards agricultural season results, extreme early season rainfall may be tempered by the large variability in the remaining season. Conversely, a lack of remaining variability gives an early indication of seasonal certainty. The techniques presented here capture the rainfall conditions in such a way as to frame them both against similar growing intervals, rather than calendar intervals, and also play those conditions out for the remainder of the season to give a sense of the remaining uncertainty. Providing this information to decision makers can assist in determining the timing and amount of aid needed to mitigate food shortages resulting from poor rainfall performance.

Acknowledgments This work was supported by the Famine Early Warning Systems Network and USGS award \#G09AC00001.

Open Access This article is distributed under the terms of the Creative Commons Attribution License which permits any use, distribution, and reproduction in any medium, provided the original author(s) and the source are credited.

\section{References}

AGRHYMET (1996) Méthodologie de suivi des zones à risque. In: AGRHYMET FLASH (ed) Bulletin de Suivi de la Campagne Agricole au Sahel, 2nd edn. Centre Regional AGRHYMET, Niamey

Artan G, Gadain H, Smith JL, Asante K, Bandaragoda CJ, Verdin JP (2007) Adequacy of satellite derived rainfall data for stream flow modeling. Nat Hazard 43:167-185

Crespo O, Hachigonta S, Tadross M (2011) Sensitivity of Southern African maize yields to the definition of sowing dekad in a changing climate. Clim Chang 106:267-283

Dinku T, Chidzambwa S, Ceccato P, Connor S, Ropelewski C (2008) Validation of high-resolution satellite rainfall products over complex terrain. Int J Remote Sens 29:4097-4110

Food and Agriculture Organization of the United Nations (2008) The state of food insecurity in the world, 2008: high food prices and food security - threats and opportunities. Food and Agriculture Organization of the United Nations, Rome
Food and Agriculture Organization of the United Nations (2009) The state of food insecurity in the world, 2009: economic crisesimpacts and lessons learned. Food and Agriculture Organization of the United Nations, Rome

Food and Agriculture Organization of the United Nations (2011) The state of food insecurity in the world: how does international price volatility affect domestic economies and food security? Food and Agriculture Organization of the United Nations, Rome

Frere M, Popov GF (1986) Agrometeorological crop yield forecasting. FAO, Rome

Funk C, Budde ME (2009) Phenologically-tuned MODIS NDVI-based production anomaly estimates for Zimbabwe. Remote Sens Environ 113:115-125

Funk C, Verdin JP (2009) Real time decision support systems: the Famine Early Warning System Network. In: Mekonnen G, Hossain F (eds) Satellite rainfall applications for surface hydrology, 327th edn. Springer, New York

Funk C, Michaelsen J, Verdin J, Artan G, Husak G, Senay G, Gadain H, Magadazire T (2003) The collaborative historical African rainfall model: description and evaluation. Int J Climatol 23:4766

Funk C, Husak GJ, Michaelsen J, Love T, Pedreros D (2007) Third generation rainfall climatologies: satellite rainfall and topography provide a basis for smart interpolation. In: Crop and Rangeland Monitoring Workshop, Nairobi, Kenya

Gelb AH, World Bank (2000) Can Africa claim the 21st century? 278th edn. World Bank, Washington

Harrison L, Michaelsen J, Funk C, Husak G (2011) Effects of temperature changes on maize production in Mozambique. Clim Res 46:211-222

Sawunyama T, Hughes DA (2008) Application of satellite-derived rainfall estimates to extend water resource simulation modelling in South Africa. Water SA 34:1-9

Senay GB, Verdin J (2003) Characterization of yield reduction in Ethiopia using a GIS-based crop water balance model. Can J Remote Sens 29:687-692

Tadesse T, Haile M, Senay G, Wardlow BD, Knutson CL (2008) The need for integration of drought monitoring tools for proactive food security management in sub-Saharan Africa. Nat Res Forum 32:265-279

Tadross MA, Hewitson BC, Usman MT (2005) The interannual variability of the onset of the maize growing season over South Africa and Zimbabwe. J Clim 18:3356-3372

Verdin J, Klaver R (2002) Grid-cell-based crop water accounting for the famine early warning system. Hydrol Processes 16:16171630

Verdin J, Funk C, Senay G, Choularton R (2005) Climate science and famine early warning. Philos Trans R Soc B Biol Sci 360:21552168

Wani S, Sreedevi T, Rockström J, Ramakrishna Y (2009) Rainfed agriculture - past trends and future prospects. In: Wani S, Rockström J, Oweis T (eds) Rainfed agriculture: unlocking the potential. CABI, Oxford

World Food Programme (2011) 2010 food aid flows. FAO, Rome

Xie P, Arkin PA (1997) Global precipitation: a 17-year monthly analysis based on gauge observations, satellite estimates, and numerical model outputs. Bull Am Meteorol Soc 78(11):2539-2558 